\title{
Oxygen Consumption
}

National Cancer Institute

\section{Source}

National Cancer Institute. Oxygen Consumption. NCI Thesaurus. Code C123570.

The rate at which oxygen is absorbed and utilized by any given tissue in the body. 